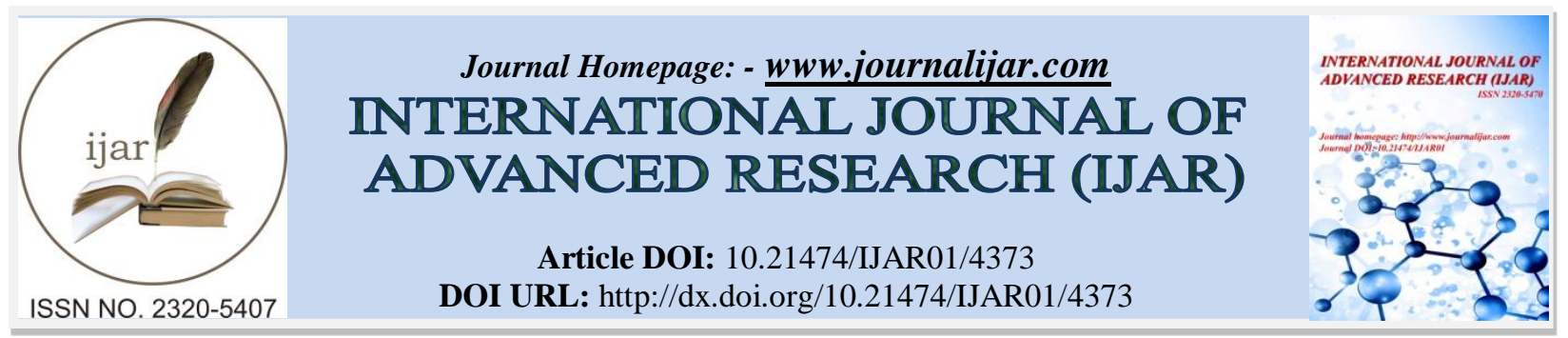

RESEARCH ARTICLE

\title{
TO DETERMINE THE LEVELS OF FREE-FATTY ACID, LIPID-PEROXIDATION AND THE ROLE OF NON- ENZYMATIC ANTIOXIDANT IN PRE-ECLAMPSIA COMPARED WITH NORMAL PREGNANCY.
}

\author{
Shweta Dwivedi ${ }^{1}$, Urvashi Singh ${ }^{2}$ and Afreen Arsad Chowdhary ${ }^{3}$. \\ 1. Assistant Professor, Department of Biochemistry MLN Medical College, Allahabad. \\ 2. Associate Professor, Department of Obs \& Gynae, MLN Medical College, Allahaba. \\ 3. Demonstrator, Department of Biochemistry, MLN Medical College, Allahabad.
}

\section{Manuscript Info}

Manuscript History

Received: 26 March 2017

Final Accepted: 31 April 2017

Published: May 2017

Key words:-

pre-eclampsia, oxidative stress, free fatty acid, lipid-peroxidation

\section{Abstract}

Preeclampsia is a hypertensive disorder and is one of the most leading causes for maternal and fetal mortality in developing countries. The aim of the present study was to determine the relationship of serum levels of free fatty acid, non-enzymatic antioxidant (Vit E\& Vit C) and lipid-peroxidation assessed by levels of malondialdehyde in preeclampsia. The study population consisted of 100 pre-eclamptic patients and 100 matched healthy pregnant women. Serum levels of free fatty acid assessed using commercially available Kit assay methods. The amount of malondialdehyde was determined by the thiobarbituric acid assay, Vitamin E and Vitamin $\mathrm{C}$ by Emer Engel and Carl A Burtis Method. Statistical analysis was performed using the student $t$ test analysis. Serum levels of malondialdehyde were significantly increased in preeclamptic group compared with normal pregnant women. Higher level of lipid-peroxidation in serum is a marker of oxidative stress which play important role in the etiopathaogenesis of preeclampsia in pregnancy.

Copy Right, IJAR, 2017,. All rights reserved.

\section{Introduction:-}

Preeclampsia, a pregnancy specific syndrome, is a major cause of maternal and perinatal morbidity and mortality. The exact mechanism underlying etiology of preeclampsia remains elusive (Abbasalizadeh et al., 2007; Ghazavi et al., 2008; Moslemizadeh et al., 2008; Savvidou et al., 2008). Preeclampsia is associated with chronic immune activation and many of these factors have been shown to play a role in mediating endothelial dysfunction during pregnancy $(5,6,7-10)$. Oxidative stress may mediate endothelial cell dysfunction and contribute to the pathophysiology of preeclampsia as there is evidence of increased pro-oxidant activity formation along with decreased anti-oxidant protection in preeclampsia. Superoxide dismutase (SOD) levels are decreased and reduced SOD activity reported in neutrophils and placentas of preeclamptic women (11). Due to metabolic changes and low grade inflammation, pregnancy is a condition of increased susceptibility to oxidative stress [12], [13]. Several organs in pregnancy show increased basal oxygen consumption and changes in substrate energy use resulting in increased mitochondrial mass and production of reactive oxygen species (ROS) [14]. The placenta is another local source of free radicals. It produces nitric oxide (NO), but also, because it's so rich with free radical producing macrophages, it can contribute to the development of oxidative stress [15], [16]. Markers of oxidative stress like serum triglycerides, free fatty acids, and malondialdehyde are increased in pre-eclampsia, are positively correlated, 
and decrease within 48 hours postpartum.[17] A significant elevation of fasting serum triglyceride level was found at 10 weeks of gestation in mild and severe pre-eclampsia.[18] Placental ceruloplasmin, a protein with antioxidant properties, expression is up-regulated in the pre-eclampsia group vs. patients matched for gestational age.[19] Possibly, placental hypoxia associated with pre-eclampsia increases placental ceruloplasmin expression as has been noted for macrophages and monocytes.[20] This study aims to assess the lipid profile and ceruloplasmin as markers for predicting the development of pre-eclampsia. The results may give an insight into the pathophysiology of gestational hypertension and pre-eclampsia. Early markers will further help us in screening those cases that have a high probability of developing pre-eclampsia, which is one of the major causes of maternal and fetal mortality. Antioxidants are being considered as prophylactic agents in the prevention of preeclampsia \& other complication of pregnancy. Placental oxidative stress is controlled by the interception destruction or modification of ROS through the action of antioxidant system can be divided into two major groups; enzymatic or non-enzymatic. There are varieties of non-enzymatic antioxidants including for eg. Glutathione, Vitamin C, Vitamin E, Vitamin A, lycopenes, selenium compounds, lipoic acid \& ubiquiniones. This study includes the study of Free Fatty acid, lipidperoxidation, superoxide-dismutase \& serum Vitamin C \& Vitamin E in pre-eclamptic women compared to healthy pregnant women (without any complication).

\section{Material and Methods:-}

This study was performed in 100 pregnant women (in their iiir ${ }^{\text {rd }}$ trimester pregnancy) age groups 20-35 years. All the subjects are divided into two groups:- study group \& control group. The study was undertaken in the Department of Biochemistry and department of gynecology, M.L.N. Medical College. Detailed history was undertaken was including age, parity, obstetric history \& presence of any risk factor, proper and complete clinical \& obstetrical examination were done at the time of antenatal visit $\&$ also at the time of admission.

Preeclampsia is defined as pregnancy induced hypertension associated with proteinurea $>0.3 \mathrm{gm} / 1$ in a 24 hour urine collection or greater than $1 \mathrm{gm} / 1$ in a random sample after 20 weeks of gestation.

Parameter: - MDA, SOD, Vitamin E, Vitamin C, Free Fatty acid

Observation Table:-

\begin{tabular}{|c|c|c|c|}
\hline S.N. & Particulars & Study Group & Control Group \\
\hline 1 & MDA & $3.83 \pm 0.33$ & $2.91 \pm 0.26$ \\
\hline 2 & Superoxide-dismutase & $1284 \pm 154.99$ & $1670.84 \pm 230.30$ \\
\hline 3 & Vitamin E & $0.66 \pm 0.26$ & $0.92 \pm 0.25$ \\
\hline 4 & Vitamin C & $0.49 \pm 0.23$ & $0.82 \pm 0.41$ \\
\hline 5 & Free Fatty acid & $0.79 \pm 0.21$ & $0.48 \pm 0.13$ \\
\hline
\end{tabular}

\section{Discussion:-}

In the present study we found raised oxidative stress markers Lipid-peroxidation, Fatty acid and decreased antioxidants superoxide dis-mutase vitamin $\mathrm{E}$ and vitamin $\mathrm{C}$ in maternal serum in preeclampsia patient these findings suggest that oxidative stress markers play a significant role in pathophysiology of preeclampsia. Cumulative evidences in recent years show that a biochemical imbalance in preeclampsia occurs with an increase of oxidative stress and a deficient antioxidant

protection [21, 22, 23]. Uncontrolled peroxidation alters membrane fluidity and permeability, therefore the lipid peroxides and their secondary metabolites, such as malondialdehyde (MDA, a good indicator of oxidant forces formed at a primary site), are then transported through the circulation by lipoproteins, causing damage at distant tissues. In the preeclamptic pregnancy, the oxidant/antioxidant balance of normal pregnancy is skewed to favor oxidants at the expense of antioxidants. Antioxidant defense systems include the chain-breaking antioxidants, such as vitamin $\mathrm{C}$ and vitamin $\mathrm{E}$, and the antioxidant enzymes. Lipid-phase chainbreaking antioxidants, the most important of which is probably vitamin E [24],Similarly, Villa et al. found that total FFA and individual FFAs (arachidonic, linoleic, oleic and palmitic acids) were considerably higher in women with preeclampsia than in normotensive pregnant women; he also found no relationship between total FFA concentration and insulin sensitivity. [ $\left[\frac{25]}{2}\right.$ This was so in spite of the fact that preeclampsia is characterized by increased insulin resistance and increased adrenergic activity which was associated with increased lipolytic activity, which could underlie the increased circulating levels of FFA in pre-eclamptic women. ${ }^{[25]}, \stackrel{[26]}{,}{ }^{[27]}$ It is unknown which single FFA is attributed to the cause of preeclampsia but assessment of total serum FFAs in this study may serve as a proxy measure for the 
disturbed metabolism seen in preeclamptic women. Thus, in cases with severe preeclampsia the increased levels of serum FFAs may represent a predisposing factor.

\section{Conclusion:-}

Increased FFA in maternal serum and high levels of oxidative damage in placental mitochondria may be involved in the pathogenesis of preeclampsia. Increased FFA in serum and

decreased activity of antioxidant enzyme in placenta may contribute to oxidative damage levels in placental mitochondria in women with PE.

\section{Reference:-}

1. Abbasalizadeh, F., S, Abbasalizadeh and N. Rashtchizadeh, 2007. Early diagnosis of preeclampsia by 8 and 12 $\mathrm{h}$ urine protein. J. Med. Sci., 7: 551-557. CrossRef | DirectLink |

2. Ghazavi, A., G. Mosayebi, E. Mashhadi, M.A. Shariat-Zadeh and M. Rafiei, 2008. Association of uric acid and C - reactive protein with severity of preeclampsia in Iranian women.J.MedicalSci.,8:239-243.CrossRef | Direct Link |

3. Moslemizadeh, N., K. Yousefnejad, T.G. Moghadam and S. Peyvandi, 2008. Urinary protein assessment in preeclampsia: Which sample is more suitable. Pak. J. Biol. Sci., 11: 2584-2588.CrossRef | PubMed | Direct Link |

4. Savvidou, M.D., A. Sotiriadis, C. Kaihura, K.H. Nicolaides and N. Sattar, 2008. Circulating levels of adiponectin and leptin at 23-25 weeks of pregnancy in women with impaired placentation and in those with established fetal growth restriction. Clin. Sci. (Lond.),115:219-224.PubMed |

5. Granger JP, Alexander BT, Llinas MT, Bennett WA, Khalil RA. Pathophysiology of hypertension during preeclampsia: Linking placental ischemia with endothelial dysfunction. Hypertension. 2001;38(3 Pt 2):718722. [PubMed]

6. Granger JP, Alexander BT, Bennett WA, Khalil RA. Pathophysiology of pregnancy-induced hypertension. Microcirculation. 2002;9:147-160. [PubMed]

7. Roberts L, LaMarca D, Fournier L, Bain J, Cockrell K, Granger JP. Enhanced Endothelin Synthesis by Endothelial Cells Exposed to Sera From Pregnant Rats With Decreased Uterine Perfusion. Hypertension. 2006;47:615-618. [PubMed]

8. Conrad KP, Benyo DF. Placental cytokines and the pathogenesis of preeclampsia. Am J Reprod Immunol. 1997;37:240-249. [PubMed]

9. LaMarca BB, Bennett WA, Alexander BT, Cockrell K, Granger JP. Hypertension Produced by Reductions in Uterine Perfusion in the Pregnant Rat: Role of Tumor Necrosis Factor-\{alpha\} Hypertension. 2005a;46:10221025. [PubMed]

10. LaMarca BB, Cockrell K, Sullivan E, Bennett W, Granger JP. Role of Endothelin in Mediating Tumor Necrosis Factor-Induced Hypertension in Pregnant Rats. Hypertension. 2005b;46:82-86. [PubMed]

11. Walsh SW. Maternal-placental interactions of oxidative stress and antioxidants in preeclampsia. Semin Reprod Endocrinol. 1998; 16:93-104. [PubMed]

12. C. Rusterholz, S. Hahn, and W. Holzgreve, "Role of placentally produced inflammatory and regulatory cytokines in pregnancy and the etiology of preeclampsia," Semin. Immunopathol., vol. 29, pp.151-162, 2007.

13. J. R. Challis, C. J. Lockwood, L. Myatt, J. E. Norman, J. F. Strauss, and F.Petraglia,"Inflamation and pregnancy," Reproductive Science, vol. 16, no 2, pp. 206-215, 2009.

14. V. Toescu, S. L. Nuttall, U. Martin, M. J. Kendall, and F. Dunne, "Oxidative stress and normal pregnancy," Clin. Endocrin., vol. 57, no.5, pp. 609-613, 2002.

15. J. Dotsch, N. Hogen, Z. Nyul, J. Hanze, I. Knerr, and M. Kirschbaum, "Increase of endothelial nitric oxide synthase and endothelin-1 mRNA expression in human placenta during gestation," Eur. J. Obstet.Gynecol. Reprod. Biol., vol. 97, pp. 163-167, 2001.

16. L. Myatt and X. Cui, "Oxidative stress in the placenta," Histochem. Cell Biol., vol. 122, pp. 369-382, 2004

17. Hubel CA, McLaughlin MK, Evans RW, Hauth BA, Sims CJ, Roberts JM. Fasting serum triglycerides, free fatty acids, and malondialdehyde are increased in preeclampsia, are positively correlated, and decrease within 48 hours postpartum. Am J Obstet Gynecol. 1996;174:975-82. [PubMed]

18. Gratacós E, Casals E, Sanllehy C, Cararach V, Alonso PL, Fortuny A. Variation in lipid levels during pregnancy in women with different types of hypertension. Acta Obstet Gynecol Scand. 1996;75:896-901. [PubMed] 
19. Guller S, Buhimschi CS, Ma YY, Huang ST, Yang L. Placental expression of ceruloplasmin in pregnancies complicated by severe preeclampsia. Lab Invest. 2008;88: 1057-67. [PMC free article] [PubMed]

20. Sarkar J, Seshadri V, Tripoulas NA, Ketterer ME, Fox PL. Role of ceruloplasmin in macrophage iron efflux during hypoxia. J Biol Chem. 2003;278: 44018-24. [PubMed]

21. Wang Y, Walsh SW. Placental mitochondria as a source of oxidative stress in pre-eclampsia. Placenta1998;19(8):581-586.

22. Suhail M, Faizul-Suhail M, Hina K. Alterations in antioxidant and pro-oxidant balance in preeclampsia. Impact on Erythrocyte Osmotic fragility. Biochemia Medica 2008; 18(3):331-341.

23. Suhail M, Faizul Suhail M, Khan H. Role of vitamins $C$ and $E$ in regulating antioxidant and pro-oxidant markers in preeclampsia. J Clin Biochem Nutr 2008;43(3):210-220.

24. Lowe DT. Nitric oxide dysfunction in the pathophysiology of preeclampsia. Nitric Oxide 2000;4(4):441-458.

25. Villa PM, Laivuori H, Kajantie E, Kaaja R. Free fatty acid profiles in preeclampsia. Prostaglandins Leukot Essent Fatty Acids. 2009;81:17-21

26. Kaaja R, Laivuori H, Laakso M, Tikkanen MJ, Ylikorkala O. Evidence of a state of increased insulin resistance in preeclampsia. Metabolism. 1999;48:892-896

27. Schobel HP, Fischer T, Heuszer K, Geiger H, Schmieder RE. Preeclampsia a state of sympathetic overactivity. N Engl J Med. 1996;335:1480-1485. 